\title{
Arachidonic Acid Metabolism Is Altered in Sarcoid Alveolar Macrophages ${ }^{1,2}$
}

\author{
Peter R. Bachwich, Joseph P. Lynch III, ${ }^{3}$ and Steven L. Kunkel \\ Division of Pulmonary and Critical Care Medicine, Department of Internal Medicine, and \\ Department of Pathology, University of Michigan Medical School, Ann Arbor, Michigan
}

\begin{abstract}
Mac: lages produce various arachidonic acid (AA) metabolites which may either enhance or suppress inflammatory processes. We investigated AA metabolite production by alveolar macrophages (AMs) from 11 paticnts with pulmonary sarcoidosis and 9 normal volunteers. We assessed the production of both cyclooxygenase products (prostaglandin ( $\mathrm{PG}) \mathrm{E}_{2}$, thromboxane $\mathrm{B}_{2}\left(\mathrm{TXB}_{2}\right), \mathrm{PGF}_{2 \alpha}$, and 6-keto- $\mathrm{PGF}_{1 \alpha}$ ) and lipoxygenase products (leukotrienes (LT) and hydroxyeicosatetraenoic acids (HETEs)) in AM cultures. We found that sarcoid AMs produced less $\mathrm{PGE}_{2}, \mathrm{TXB}_{2}$, 6-keto-PGF $\mathrm{F}_{1 \alpha}$, and HETEs in both the unstimulated and the calcium ionophore-stimulated states compared with normal AMs. Sarcoid AMs also produced less PGF PG $_{2 u}$ and I,Ts in the unstimulated state after $1 \mathrm{hr}$ of incubation, but following calcium ionophore stimulation, these differences did not achieve statistical significance. We conclude that sarcoid AMs have a reduced capacity to produce AA metabolites compared with that of normal AMs. 1987 Academic Press, lnc
\end{abstract}

\section{INTRODUCTION}

Metabolites of arachidonic acid (AA) are important regulatory molecules which influence the intensity and duration of inflammatory processes $(1,2)$. Arachidonic acid may be metabolized by both the cyclooxygenase ( $\mathrm{CO}$ ) pathway, yielding prostaglandins (PGs) and thromboxanes, and the lipoxygenase (LO) pathway, producing leukotrienes and hydroxyeicosatetraenoic acids (HETEs) (2-4). Products of both pathways possess potent and diverse immunoregulatory effects (2-5). $\mathrm{PGE}_{2}$ and $\mathrm{PGI}_{2}$ have predominantly antiinflammatory effects, while $\mathrm{PGF}_{2 \alpha}$, thromboxane $\mathrm{A}_{2}$, and most $\mathrm{LO}$ products may potentiate inflammation $(2-4,6)$. Hence, the relative concentrations of specific AA metabolites may influence the direction of an inflammatory reaction, either to amplification or to resolution. Prostaglandins of the E series exert predominantly immunosuppressive effects and may function as important modulators of cellular immune responses $(5,7,8)$. Both exogenous administration of $E$ series PGs and endogenous production of $\mathrm{PGE}_{2}$ by mononuclear phagocytes have been shown to suppress several important lymphocyte and macrophage (MØ) functions. $\mathrm{PGE}_{2}$ inhibits T-cell proliferation (3) and natural killer cell activity (3), induces the expression of T sup-

\footnotetext{
1 Presented in part at the $\Lambda$ spen Lung Conference, Aspen, Colorado, in June 1985.

${ }^{2}$ Joseph P. Lynch III is supported in part by a grant from the American Lung Association, and Steven L. Kunkel by Public Health Services Grants HL31237 and HL31963 from the National Institutes of Health. Kunkel is an established investigator of the American Heart Association.

${ }^{3}$ To whom all correspondence and reprint requests should be sent, at Pulmonary and Critical Care Medicine, University of Michigan Hospital, 3916 Taubman Center, Ann Arbor, Mich. 48109.
} 
pressor cell phenotype (9), reduces Ia and HLA-DR antigen expression by immune effector cells (6), and inhibits monokine release (10). The role of lipoxygenase products in the expression and modulation of inflammatory processes is less clear. However, certain LO products are potent chemotactic agents, stimulate cellular aggregation and degranulation, and stimulate $\mathrm{T}$-cell mitogenesis and monokine release $(2,4,11)$, thereby promoting inflammation. Macrophages are important sources of AA metabolites compared with other immune effector cells, as they are unusually rich in arachidonic acid and possess the ability to metabolize AA by either pathway $(1,2,12)$. Although many factors determine the amount and types of AA metabolites produced, the activation state of the macrophage has special importance $(2,12-14)$. Several investigators have demonstrated that chemically elicited or immunologically activated $\mathrm{M} \emptyset$ s produce less AA metabolites than resident $M \emptyset_{\mathrm{s}}(2,12-14)$. Further, the amount and type of AA metabolites may change with evolution of inflammatory processes and are subject to immunomodulatory influences. For example, $\mathrm{M} \emptyset_{\mathrm{s}}$ isolated from murine hypersensitivity lung granulomas demonstrate an initial increase in the quantities and complexity of AA metabolites as the acute granulomatous process develops $(2,15)$, but release lesser amounts of PGs and exhibit decreased ability to metabolize AA in later phases of granuloma formation (15). Whether similar changes in AA metabolism occur in chronic granulomatous diseases in man has not, to our knowledge, been investigated. Since pulmonary sarcoidosis is a granulomatous disorder in which interactions between activated alveolar macrophages and $\mathrm{T}$ lymphocytes are important in the pathogenesis (16-18), we investigated arachidonate metabolism by $\mathrm{AMs}$ isolated by bronchoalveolar lavage from patients with sarcoidosis and normal controls. We demonstrated a decreased production of cyclooxygenase and lipoxygenase products by sarcoid AMs, suggesting down-regulation. Hence, changes in AA metabolites produced by macrophages may influence the direction and extent of granulomatous responses.

\section{MATERIALS AND METHODS}

Patient population. Bronchoalveolar lavage (BAL), utilizing the flexible fiberoptic bronchoscope, was performed in 11 nonsmoking patients with sarcoidosis as part of the initial diagnostic evaluation of an abnormal chest roentgenogram. Transbronchial lung biopsy demonstrated noncaseating granulomas in all cases, and other granulomatous diseases were reliably excluded. Two sarcoid patients were roentgenographic stage I, eight were stage II, and one was stage III. Pulmonary function tests were normal in six and showed a restrictive defect in five. As a group, the patients with sarcoidosis had the following pulmonary function abnormalities (mean as a percentage of predicted \pm standard deviation): forced vital capacity (FVC) 77.1 上 $15.1 \%$, total lung capacity (TLC) $79.5 \pm 9.5 \%$, and single breath diffusing capacity $\left(\mathrm{D}_{\mathrm{L}} \mathrm{CO}\right) 80.4 \pm 12.2 \%$. Six of 11 patients had symptoms of cough or dyspnea attributable to pulmonary sarcoidosis. Based on clinical criteria, five of the symptomatic patients were judged to have active disease and were subsequently treated with corticosteroids. The remaining patients were considered to have clinically inactive disease and were not treated. No patient was receiving steroids, immunosuppressive agents, or nonsteroidal antiin- 
flammatory agents at the time of BAL. Although $\mathrm{CO}$ metabolic products were assessed in all 11 patients, LO metabolism was evaluated in only the last five patients in the study. Two of these five were symptomatic, had mild restrictive defects on pulmonary function tests, and were judged to have clinically active disease. The remaining three sarcoid patients were asymptomatic, had normal pulmonary function, and were considered to have clinically inactive disease. There were no significant clinical, roentgenographic, or physiological differences between these five sarcoid patients who had LO products determined compared with the remaining six sarcoid patients or the group as a whole. Nine normal nonsmoking volunteers were recruited as control subjects. All were asymptomatic and had normal chest roentgenograms and pulmonary function tests. None was receiving medication at the time of BAL. None of the patients or normal volunteers had signs of an infectious process within 6 weeks of the time of BAL.

Technique of bronchoalveolar lavage. Bronchoalveolar lavage was performed using standard methods (16-19). After premedication with intramuscular atropine and codeine, topical anesthesia was achieved with nebulized $4 \%$ lidocaine to the oropharynx and $2 \%$ lidocaine to the trachea and bronchi. Following brief visual inspection of the airways, the tip of the bronchoscope was gently wedged into a subsegmental bronchus of the right middle lobe or lingula, and $30-\mathrm{ml}$ aliquots of sterile normal saline were instilled via the suction channel of the bronchoscope and immediately aspirated into a sterile collection chamber. This process was repeated for a total instillation of $240 \mathrm{ml}$. Of the instilled fluid, 50 to $75 \%$ was usually recovered.

Preparation of AM suspension. Recovered BAL fluid was filtered and centrifuged at $400 \mathrm{~g}$, and the pellet was resuspended in sterile RPMI 1640 (Grand Island Biological Co., Grand Island, N.Y.). Total cell count was performed using a hemacytometer. A cell differential was obtained by counting 500 cells on slides stained with Papanicolaou's stain. The cell suspension was then washed three times and resuspended to a final concentration of $1 \times 10^{6} \mathrm{cell} / \mathrm{ml}$ in sterile RPMI 1640 with $10 \%$ fetal calf serum (K. C. Biological, Lenexa, Kan.) and $20 \mathrm{mcg} / \mathrm{ml}$ of gentamicin (complete media).

Assays for cyclooxygenase products. One milliliter of the cell suspension was added to $35-\mathrm{mm}$ plastic tissue culture plates (Corning Glass Works, Corning, N.Y.) and was incubated at $37^{\circ} \mathrm{C}$ in $5 \% \mathrm{CO}_{2} / 95 \%$ air for $4 \mathrm{hr}$. The plates were rinsed twice vigorously to remove nonadherent cells, and $1.5 \mathrm{ml}$ of RPMI 1640 with $30 \mathrm{mcg}$ of gentamicin (serum-free media) was added to each plate. The plates were incubated for an additional $16 \mathrm{hr}$, and the supernatants were collected and frozen at $-20^{\circ} \mathrm{C}$. The adherent cells were washed with warm RPMI twice, and $1.5 \mathrm{ml}$ of serum free media was added to each plate. Half of the plates received calcium ionophore A23187 in a final concentration of $10^{-5} \mathrm{M}$. After $1 \mathrm{hr}$ of incubation at $37^{\circ} \mathrm{C}$ in $5 \% \mathrm{CO}_{2} / 95 \%$ air, the supernatants were collected and frozen. Viability of the adherent cells as determined by trypan blue exclusion was greater than $90 \%$ in all cases. The number of adherent cells was quantitated by direct counting of monolayers stained with Wright's stain. The adherent cells were routinely $>95 \%$ macrophages based on nuclear morphological criteria, phagocytosis of inert latex beads, and positive staining for nonspecific esterase. Supernatants 
were assayed for $\mathrm{PGE}_{2}, \mathrm{PGF}_{2 \alpha}$, thromboxane $\mathrm{B}_{2}$, and 6-keto-PGF $\mathrm{F}_{1 \alpha}$ using radioimmunoassays as described by Fitzpatrick and co-workers $(20,21)$. Briefly, protein and free fatty acids were extracted from the samples prior to the addition of antibodies. Bound and free ligand were separated using dextran-coated charcoal. All assays were run in duplicate.

Assays for lipoxygenase products. To evaluate lipoxygenase pathway metabolism, alveolar macrophage suspensions from five of the normals and five of the sarcoid patients were obtained by methods described above. Two milliliters of the cell suspension was applied to each $60-\mathrm{mm}$ tissue culture plate (Lab-Tek, Miles Laboratories). After $4 \mathrm{hr}$ of incubation at $37^{\circ} \mathrm{C}$ in $5 \% \mathrm{CO}_{2} / 95 \%$ air, nonadherent cells were removed, and $2 \mathrm{ml}$ of serum-free media containing $1 \mu \mathrm{Ci}$ of $\left[{ }^{3} \mathrm{H}\right] \mathrm{AA}(91$ $\mathrm{Ci} / \mathrm{mmol}$ sp act; New England Nuclear, Boston Mass.) was added to each plate. Following an additional $16 \mathrm{hr}$ of incubation, the plates were washed with warm RPMI to remove unincorporated radiolabel. Two milliliters serum-free media was then added to each dish, with half of the plates receiving $10^{-5} M$ A23187. After a $1 \mathrm{hr}$ incubation, the dishes were scraped to resuspend the adherent macrophages. and AA metabolites were extracted as follows. The cell-containing media were collected and acidified to $\mathrm{pH} 3$ with $1 \mathrm{~N} \mathrm{HCl}$, then extracted twice with 3 vol of ethyl acetate. The solvent was evaporated using a Speed Vac concentrator (Savant Instruments, Hicksville, N.Y.). Extracts were stored under $100 \% \mathrm{~N}_{2}$ at $-20^{\circ} \mathrm{C}$, then were dissolved in $0.1 \mathrm{ml}$ absolute methanol just prior to column chromatography. Metabolites of AA were identified by reverse-phase high performance liquid chromatography (HPLC) using a modified method of Van Rollins et al. (22). One-tenth-milliliter samples were applied to $5 \mu \mathrm{m} \mathrm{C}$ - 18 reverse phase $(30$ $\times 0.4 \mathrm{~cm}$ ) column (Varian Associates, Palo Alto, Calif.) at $29^{\circ} \mathrm{C}$ with a $1 \mathrm{ml} / \mathrm{min}$ flow rate. The solvent system containing acetonitrile (Burdick and Jackson Laboratories, Muskegon, Mich.)/water/trifluoroacetic acid (Pierce Chemical Co., Rockford, Ill.) was used as described previously (23). The eluate was continuously monitored for ultraviolet absorbance and radioactivity (23). The column was calibrated using radiolabeled and unlabeled known standards. Unlabeled leukotrienes (LTs) were kindly provided by Dr. J. Rokach (Merck Frost Laboratories, Quebec, Canada), and 5- and 12-HETE were kindly provided by Dr. J. Pike and Dr. Robert Gorman (Upjohn Co., Kalamazoo, Mich.). ${ }^{14} \mathrm{C}$-labeled $\mathrm{LTB}_{4}$ was provided by Henry Showell (Pfizer Central Research, Groton, Conn.). $\left[{ }^{3} \mathrm{H}\right] \mathrm{LTC} \mathrm{C}_{4}$ and $\left[{ }^{3} \mathrm{H}\right] \mathrm{AA}$ were purchased from New England Nuclear.

For purposes of data analysis, the elution peaks corresponding to $\mathrm{LTB}_{4}$ and $\mathrm{LTC}_{4}$ and the peaks corresponding to 5-HETE, 12-HETE, and 15-HETE were pooled, respectively, for quantitation of leukotrienes and monohydroxyeicosatetraenoic acids (mono-HETEs).

Statistical analysis. Statistical analysis was performed using the unpaired Student's $t$ test. $P$ values of less than 0.05 were considered significant. Data are expressed as means \pm standard error of the means.

\section{RESULTS}

Total Cell and Differential Counts of BAL

Bronchoalveolar lavage in the normals revealed a mean cell count of $16.5 \pm 2.1$ 
million which comprised a mean of $9.8 \pm 2.0 \%$ lymphocytes, $88.4 \pm 2.0 \%$ alveolar macrophages, and $1.8 \pm 0.6 \%$ neutrophils. These data are comparable with results published in normals by other investigators $(11,13,36)$. The mean BAL count in the 11 sarcoid patients (34.4 \pm 5.4 million) was significantly greater compared with that of normal volunteers $(P<0.005)$. Mean percentage lymphocytes on BAL differential count also was significantly greater in the sarcoid patients (mean $31.9 \pm 4.0 \%)$ when compared with that of normal volunteers $(P<$ $0.001)$. Mean percentage BAL polymorphonuclear leukocytes in the sarcoid patients $(0.8 \pm 0.3)$ was not significantly different compared with that in the normal volunteers $(P>0.2)$.

\section{Cyclooxygenase Products}

Sarcoid AMs produced less CO metabolites than AMs from normal volunteers both in the resting and ionophore-stimulated states. Following $1 \mathrm{hr}$ incubation, sarcoid $\mathrm{AMs}$ produced less $\mathrm{PGE}_{2}$ compared with normals both in the resting state $(P<0.01)$ and following stimulation by calcium ionophore $(P<0.001$; Fig. 1$)$. After $16 \mathrm{hr}$ of incubation, unstimulated sarcoid AMs produced less $\mathrm{PGE}_{2}$ than did unstimulated normal AMs $(P<0.001)$ as shown in Fig. 2.

Sarcoid AMs also produced less thromboxane $B_{2}$ after $1 \mathrm{hr}$ incubation in both the resting and ionophore-stimulated state compared with normal AMs $(P<0.01$; Fig. 1). After $16 \mathrm{hr}$ of incubation, unstimulated sarcoid AMs produced threefold less thromboxane $\mathrm{B}_{2}$ than did normal AMs $(P<0.05$; Fig. 2).

Sarcoid AMs produced significantly less 6-keto-PGF $F_{1 \alpha}$ after $1 \mathrm{hr}$ in both the resting and ionophore-stimulated states compared with normal AMs $(P<0.005$, both comparisons; Fig. 1). Unstimulated sarcoid AMs also produced less 6-keto$\mathrm{F}_{1 \alpha}$ following $16 \mathrm{hr}$ incubation compared with normal AMs $(P<0.003$; Fig. 2).

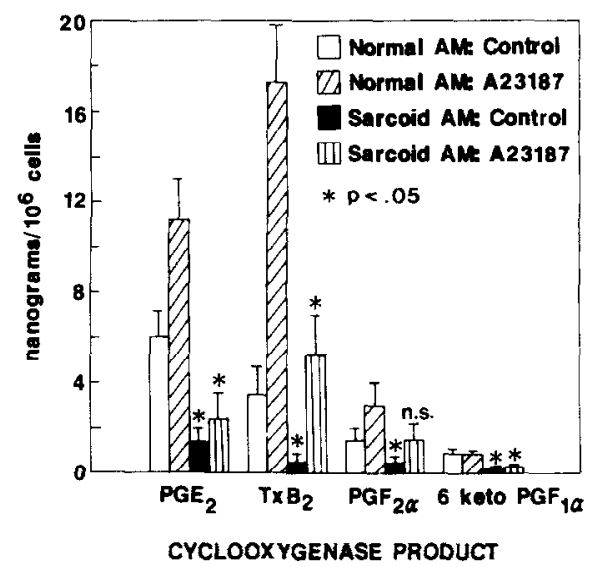

FIG. 1. Cyclooxygenase metabolite production by human alveolar macrophages after $1 \mathrm{hr}$ of incubation with and without $10^{-5} M$ A23187. Metabolite production is expressed as nanograms/million cells. * denotes statistical significance comparing normal and sarcoid AMs incubated under similar conditions. Compared with normal AMs, unstimulated sarcoid AMs produce significantly less PGE , $_{2}$

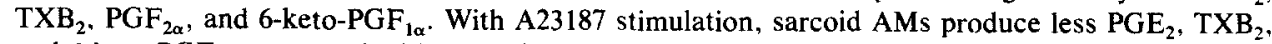
and 6-keto $\mathrm{PGF}_{1 \alpha}$ compared with normal AMs. 


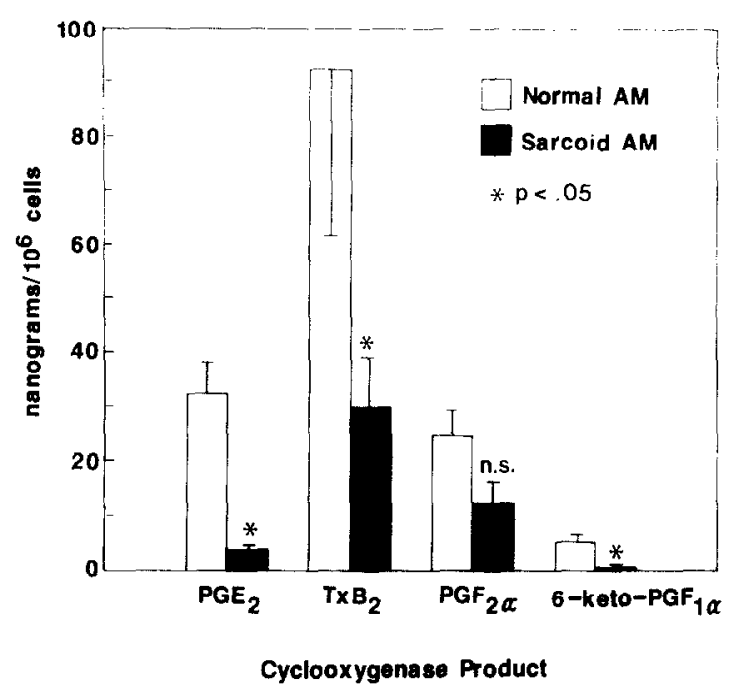

FIG. 2. Cyclooxygenase metabolite production by human alveolar macrophages after $16 \mathrm{hr}$ of incubation without exogenous stimuli. Metabolite production is expressed as nanograms/million cells. Compared with normal AMs, sarcoid AMs produce significantly less $\mathrm{PGE}_{2}$. TXB 2 , and 6-keto-PGF $\mathrm{P}_{1 \alpha}$.

Unstimulated sarcoid AMs produced significantly less PGF $_{2 \alpha}$ after 1 hr incubation compared with normals (Fig. $1 ; P<0.05$ ). With calcium ionophore stimulation, differences between sarcoid and normal AMs at $1 \mathrm{hr}$ did not achieve statistical significance. After $16 \mathrm{hr}$ of incubation, $\mathrm{PGF}_{2 \alpha}$ production did not differ significantly between unstimulated sarcoid and normal AMs $(P>0.10$; Fig. 2).

\section{Lipoxygenase Products}

Unstimulated sarcoid AMs produced less LTs and less HETEs after $1 \mathrm{hr}$ of incubation compared with normal AMs $(P<0.03$ and $P<0.02$, respectively; Fig. 3). Following stimulation with calcium ionophore, sarcoid AMs produced less HETEs than did normal AMs, but there was no significant difference in LT production between sarcoid and normal AMs (Fig. 3). A representative HPLC profile is depicted in Fig. 4.

\section{Correlation of AA Metabolite Production and Clinical Activity}

There was no correlation between production of either CO or LO pathway metabolites and the clinical assessment of disease activity. Specifically, AA metabolite production did not correlate with symptoms, chest roentgenographic stage, pulmonary function testing, or BAL total cell count or lymphocyte count.

\section{DISCUSSION}

Pulmonary sarcoidosis is a disease in which interactions between activated lung $\mathrm{T}$ lymphocytes and mononuclear phagocytes appear to be responsible for the induction and evolution of the granulomatous inflammatory lesion $(16-19,24)$. The sarcoid granuloma is comprised predominantly of monocyte-macrophagederived cells (epithelioid cells, multinucleated giant cells) within the central core, 


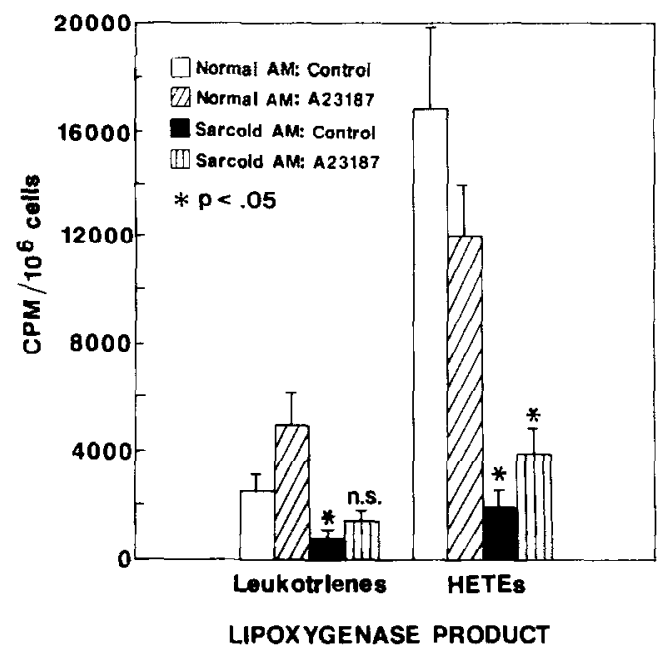

FIG. 3. Lipoxygenase metabolite production by human alveolar macrophages after $1 \mathrm{hr}$ of incubation with and without A23187 stimulation. Leukotriene and HETE production is expressed as counts per minute/million cells. * denotes statistical significance comparing normal and sarcoid AMs incubated under similar conditions. Compared with normal AMs, unstimulated sarcoid AMs produce less leukotrienes and less HETEs. After A23187 stimulation, sarcoid AMs produce less HETEs than do normal AMs.

surrounded by lymphocytes in the periphery $(16,17,24)$. This granulomatous response, however, appears to be preceded by an alveolitis composed of activated lymphocytes and mononuclear phagocytes $(16,17,24)$. Increased numbers of alveolar macrophages $(16,17,19)$, activated $\mathrm{T}$ cells $(16-18,24)$, and $\mathrm{T}$ helper cells $(17,18)$, with decreased numbers of $T$ suppressor cells $(17,18)$, have been demonstrated in BAL fluid in patients with active pulmonary sarcoidosis, indicating a heightened cellular immune response in the lung. Among these various immune effector cells, the alveolar macrophage represents a key cell in the formation of the sarcoid granuloma by virtue of its prominence in the histopathology

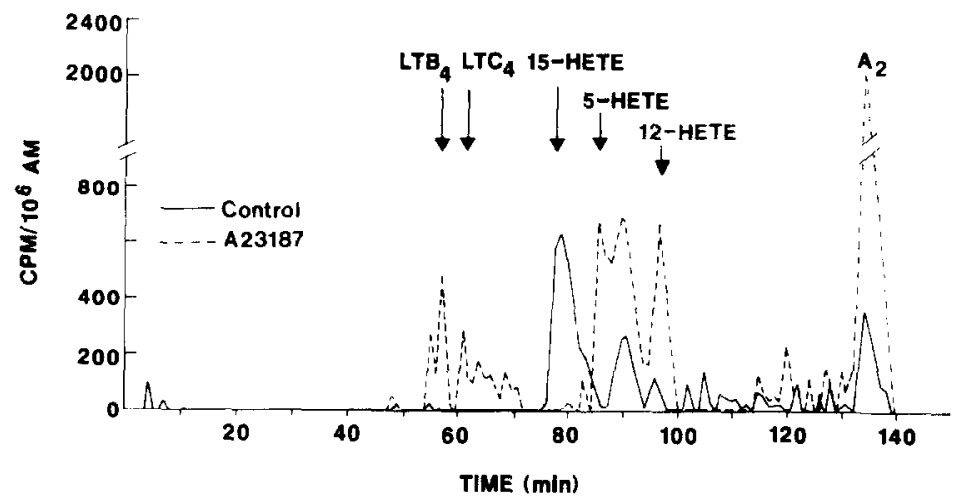

FrG. 4. A representative HPLC profile of LO metabolite production by human alveolar macrophages from a patient with sarcoidosis. The elution peaks are identified by comparison with labeled known standards. 
of the reaction, its ability to actively interact with $T$ lymphocytes $(16,25)$, and its potency as a secretory cell $(2,26)$. Several features suggesting activation of the alveolar macrophage in sarcoidosis have been demonstrated. Sarcoid AMs obtained by BAL contain increased amounts of lysozyme and angiotensin-converting enzyme (27), have morphological features consistent with an activated state $(16,17,27)$, display enhanced DR antigen expression (24) and antigen-presenting capacity (17), and spontaneously release monokines including interleukin-1 (28), alveolar macrophage-derived growth factor (29), and fibronectin (30). These $M \emptyset$ characteristics are capable of enhancing the inflammatory and fibrotic components of the sarcoid reaction. The factors responsible for limiting or regulating the granulomatous response, however, are poorly understood. In animal models of granulomatous inflammation, macrophages have been shown to produce endogenous mediators which may influence the course of chronic inflammatory processes $(1,15)$. Of particular importance are the types and amounts of macrophage-derived arachidonate metabolites. Since $M \emptyset$ s are capable of metabolizing AA into both cyclooxygenase and lipoxygenase products $(2,12,31)$, changes in the types and quantities of AA metabolites may modulate the extent and direction of inflammatory reactions $(2,15,23,32)$. Despite the potential importance of AA metabolites in influencing chronic granulomatous inflammation, data in humans are limited.

In the present study, we demonstrated an altered ability of AMs from patients with pulmonary sarcoidosis to metabolize AA as compared with normal AMs. In addition, by utilizing both radioimmunoassays and HPLC, we have more fully characterized the spectrum of AA metabolites synthesized by normal and sarcoid AMs. In our system, the RIA detects products based on the metabolism of endogenous stores of AA, while the HPLC detects products based on the metabolism of exogenous $\left[{ }^{3} \mathrm{H}\right] \mathrm{AA}$. Thus, it must be noted that a difference in the levels of metabolites may occur depending on the mobilization of endogenous or exogenous arachidonic acid pools. Whereas previous studies of AA metabolism by human AMs have analyzed either CO products (33) or LO products (34-37), we assessed products of both pathways in normal and sarcoid AMs to better delineate the entire AA metabolic profile. We demonstrated that $\mathrm{PGE}_{2}$ and $\mathrm{TXB}_{2}$ were the predominant $\mathrm{CO}$ metabolites produced by sarcoid and normal AMs, while smaller amounts of $\mathrm{PGF}_{2 \alpha}$ and 6-keto- $\mathrm{PGF}_{1 \alpha}$ were detected. This is consistent with previous investigations demonstrating that $\mathrm{PGE}_{2}$ and $\mathrm{TXB}_{2}$ were the major CO-derived metabolites synthesized by human AMs (33). We also demonstrated that stimulation with calcium ionophore significantly increased the production of CO metabolites by both normal and sarcoid AMs. Utilizing HPLC, we found that both normal and sarcoid AMs produced mono-HETEs as the predominant LO products, but smaller amounts of leukotrienes were also detected. Among the mono-HETEs, the largest peak coeluted with the 5-HETE standard, while other smaller peaks co-migrated with standards for 12- and 15-HETE. This is consistent with the work of previous investigators $(34,36,37)$, all of whom reported that 5-HETE was the predominant mono-HETE synthesized by human AMs. Our findings differ from those of Martin et al. (36) and Laviolette et al. (37), however, as these authors failed to detect either 12- or 15-HETE. Chang and co-workers 
demonstrated 12-HETE production by human AMs (34), consistent with our findings, but were unable to detect 15-HETE synthesis. We also demonstrated that both normal and sarcoid AMs produced LTs, with the major peak coeluting with $\mathrm{LTB}_{\mathbf{4}}$. This agrees with several other reports describing $\mathrm{LTB}_{\mathbf{4}}$ as the predominant leukotriene produced by human AMs (35-37). Although most investigators have failed to detect $\mathrm{LTC}_{4}, \mathrm{LTD}_{4}$, and $\mathrm{LTE}_{4}(35-37), \mathrm{LTD}_{4}$ has been described as a metabolic product of AA by human AMs (38). Although we failed to detect $\mathrm{LTD}_{4}$, we observed a small peak of material which coeluted with $\mathrm{LTC}_{4}$, thus indicating that normal and sarcoid AMs are capable of synthesizing small quantities of $\mathrm{LTC}_{4}$.

Of particular interest in our study was the generalized reduction in AA metabolism demonstrated by sarcoid AMs compared with normal AMs. Substantial reductions in $\mathrm{PGE}_{2}, \mathrm{TXB}_{2}, 6$-keto-PGF $\mathrm{P}_{1 \alpha}$, and mono-HETE production by sarcoid AMs were observed. Reductions in $\mathrm{PGF}_{2 \alpha}$ and leukotriene release by sarcoid AMs also were demonstrated, but were smaller in magnitude. Our findings of reductions in both $\mathrm{CO}$ and $\mathrm{LO}$ metabolism by sarcoid AMs are consistent with down-regulation of AA metabolism previously demonstrated in chronically activated macrophages in animals $(2,12,39,40)$. For example, striking reductions in $\mathrm{PGE}_{2}$ synthesis have been demonstrated in murine peritoneal macrophages activated by Corynebacterum parvum, Bacille-Calmette-Guerin (BCG), or carrageenin-induced granulomas (13). Scott et al. (12) confirmed decreased production of $\mathrm{PGE}_{2}$ as well as suppression of $\mathrm{PGI}_{2}$, HETEs, and LTC synthesis by $C$. parvum and BCG-activated $\mathrm{M} \emptyset$ s compared with resident $\mathrm{M} \emptyset_{\mathrm{s}}$.

In addition to change in quantities of AA metabolites released by chronically activated $\mathrm{M} \emptyset \mathrm{s}$, the types of AA metabolic products may change as inflammatory processes evolve. For example, AA metabolites released by MØs isolated from Schistosoma egg-induced murine lung granulomas 4 days post-egg embolization are similar to the profile seen in resident peritoneal macrophages $(32,41)$. However, $M \emptyset$ s isolated at 8 and 16 days display altered arachidonate metabolism with a shift from production of 12-HETE to both 5-HETE and 12-HETE. Additional changes in $\mathrm{M} \emptyset$ arachidonate metabolism can be demonstrated at 8 and 20 weeks. $\mathrm{M} \varnothing$ isolated from 20-week granulomas release lesser amounts of PGs and exhibit reduced AA metabolism compared with the more acute (8-week), highly cellular granulomas (15). Hence, changes in the profile of AA metabolites released by $\mathrm{M} \emptyset_{\mathrm{s}}$ at sites of disease may be important in modifying the course of inflammatory processes.

The mechanism by which this down-regulation of AA metabolism occurs remains unclear. Humes $e t$ al. noted a markedly decreased rate of AA release from elicited compared with resident murine PEMs, consistent with reduced phospholipase $A_{2}$ activity (13). Whether a similar mechanism is operative in human AMs is unknown, although Laviolette and co-workers suggested that reduced phospholipase activity could explain their findings of reduced $\mathrm{CO}$ metabolite production by human smoker AMs (33). Diminished phospholipase activity could also explain the reduced production of both $\mathrm{CO}$ and LO metabolites which we observed in sarcoid AMs, but this remains speculative as we did not specifically measure phospholipase activity. In experimental models, phospholipase activity 
may be regulated by mediators released by immune effector cells. For example, $\gamma$-interferon, a product of both lymphocytes and macrophages, suppresses phospholipase activity in murine PEMs in vitro, resulting in reduced release of AA (42). This modulating effect of $\gamma$-interferon on phospholipase activity is particularly intriguing in light of Hunninghake et al.'s recent report that AMs isolated from patients with active pulmonary sarcoidosis release increased amounts of $\gamma$-interferon (43). Thus, in vivo exposure of sarcoid AMs to $\gamma$-interferon may explain the down-regulation in AA metabolism observed in our experiments.

The significant decrease in $\mathrm{PGE}_{2}$ production by AMs from sarcoid patients is potentially very important since $\mathrm{PGE}_{2}$ decreases lymphokine production (44) and lymphocyte mitogenesis (45) and suppresses a variety of monocyte and macrophage functions $(11,46-48)$. Since $\mathrm{PGE}_{2}$ is a potent suppressor of many inflammatory events, reduced release of $\mathrm{PGE}_{2}$ may intensify or perpetuate the heightened cellular immunity evident in pulmonary sarcoid. Reduced levels of $\mathrm{PGE}_{2}$ in the inflammatory environment could explain the observations of increased cytokine release, including that of $\gamma$-interferon (43), interleukin-1 (28), and interleukin-2 (52), and of increased HLA-DR antigen expression (25) and antigen presentation capacity (17) previously reported in sarcoidosis.

Since levels of $\mathrm{PGE}_{2}$ and arachidonate metabolic products did not correlate with clinical, radiographic, or physiologic indicators of disease activity in our sarcoid patients, the significance of reduced AA metabolism in sarcoidosis is not clear. Additional studies, including serial assessments of sarcoid AM arachidonate metabolism as the disease activity changes, are needed to clarify the role of altered AA metabolism in the pathogenesis of sarcoidosis.

\section{REFERENCES}

1. Bonta, I. L., Parnham, M. J., and Bragt, P. C., In "Prostaglandin Synthetase Inhibitors: New Clinical Application'” (P. Ramwell, Ed.), Liss, New York, 1980.

2. Chensue, S. W., and Kunkel, S. L., Clin. Lab. Med. 3, 677, 1983.

3. Goodwin, J. S., and Ceuppens, J., J. Clin. Immunol. 3, 295, 1983.

4. Samuelsson B., In "Leukotrienes and Other Lipoxygenase Products" (B. Samuelsson and R. Paoletti, Eds.), pp. 1-17, Raven Press. New York, 1982.

5. Goodwin, J. S., and Webb D. R., Clin. Immunol. Immunopathol. 15, 106, 1980.

6. Snyder, D. S., Beller, D. I., and Unanue, E. R., Nature (London) 299, 163, 1982.

7. Leung, K. H., Ehrke, M. J., and Mihich, E., Int. J. Immunopharmacol. 4, 195, 1982.

8. Mertin, J., and Stackpool, A.. Cell. Immunol. 62, 293, 1981.

9. Fischer, A., Durandy, A., and Griscelli. C., J. Immunol. 126, 1452, 1981.

10. Kunkel, S. L., and Chensue, S. W., Biochem. Biophys. Res. Commun. 128, 892, 1985.

11. O'Flaherty, J. T., Thomas, M. J., Lees, C. J., and McCall, C. E., Amer, J. Pathol. 104, 55, 1981.

12. Scott, W. A., Pawlowski, N. A., Murray, H. W., Andreach, M., Zrike, J., and Cohn, Z. A., J. Exp. Med. 155, $1148,1982$.

13. Humes, J. L., Burger, S., Galavage, M., Kuehl, F. A., Wightman, P. D., Dahlgren, M. E., Davies, P., and Bonney, R. J., J. Immunol. 124, $2110,1980$.

14. Scott, W. A., Zrike, J. M., Hamill, A. L., Kempe, J., and Cohn, Z. A., J. Exp. Med. 152, 324, 1980.

15. Chensue, S. W., Kunkel, S. L., Higashi, G. I., Ward, P. A., and Buros, D. L.. Infect. Immunol. $42,1115,1983$.

16. Crystal, R. C., Roberts, W. C., Hunninghake, G. W., Gadek, J. E., Fulmer, J. D., and Line, B. R., Ann. Intern. Med. 94, 73, 1981.

17. Daniele, R. P., Elias, J. A., Epstein, P. E., and Rossman, M. D., Ann. Intern. Med. 102, 93, 1985. 
18. Hunninghake, G. W., and Crystal, R. G., New Engl. J. Med. 305, 429, 1981.

19. Hunninghake. G. W., Kawanami, O., Ferrans, V. J., Young, R. C., Roberts, W. C.. and Crystal. R. G., Amer. Rev. Respir. Dis. 123, 407, 1981.

20. Fitzpatrick, F. A., and Bundy, G. L., Proc. Natl. Acad. Sci. USA 75, 2689, 1978

21. Fitzpatrick, F. A., and Wynalda, W. A., Anal. Biochem. 73, 198, 1976.

22. Van Rollins, M., Ho, S. H. K., Greenwald, J. E., Alexander, M., Dorman, N. J., Wong, L. K., and Horrocks, L. A., Prostaglandins 20, 571, 1980.

23. Kunkel, S. L.. Chensue, S. W., Mouton, C., and Higashi, H. I., J. Clin. Invest. 74, 514, 1984.

24. Hunninghake, G. W., Gadek, J. E., Young, R. C., Kawanami, O., Ferrans, V. J., and Crystal. R. G., New Engl. J. Med. 302, 594, 1980.

25. Razma, A. G., Lynch, J. P., Wilson, B. S., Ward, P. A., and Kunkel, S. L., Amer. Rev. Respir. Dis. 129, 419, 1984.

26. Davis, P., Bonney, R. J., Humes, J. L., and Kuehl, P. A., In "Mononuclear Phagocytes: Functional Aspects" (R. Van Furth, Ed.), Nijhoff, The Hague, 1980.

27. Gee, B. L., Bodel, T. P., Zorn, S. K., Hinman, L. M., Stevens, C. A., and Matthay, R. A., Lung $155,243,1978$.

28. Hunninghake, G. W., Amer. Rev. Respir. Dis. 129, 569, 1984.

29. Bitterman, P. B., Adelberg, S., and Crystal, R. G., J. Clin. Invest. 72, 1801, 1983.

30. Rennard, S. I., Hunninghake, G. W., Bitterman, P. B., and Crystal. R. G.. Proc. Natl. Acad. Sci. USA 78, 7147, 1981 .

31. Kurland, J. I.. and Bockman, R., J. Exp. Med. 147, 952, 1978.

32. Kunkel, S. L.. Chensue, S. W., Plewa, M., and Nigashi, G. I., Amer. J. Pathol. 114, $240,1984$.

33. Laviolette, R., Chang, J., and Newcombe, D. S., Amer. Rev, Respir. Dis. 124, 397, 1981.

34. Chang, J., Liu, M. C., and Newcombe, D. S., Amer. Rev. Respir. Dis. 126, 457, 1982.

35. Fels, A., Pawlowski, N., Bramer, E. B., King, T., Cohn, Z., and Scott, W., Proc. Natl. Acad. Sci. USA 79, 7866, 1982.

36. Martin, T. R., Altman, L. C., Alvert, R. K., and Henderson. W. R., Amer. Rev. Respir. Dis. 128, $106,1984$.

37. Laviolette. M., Coulombe, R., Picard, S., Braquet, D., and Borgeat, P., J. Clin. Invest. 77, 54. 1986.

38. Damon, M., Chavis, C., Godard, P. H., Michel, F. B., and Crastes de Paulet, A., Biochem. Biophys. Res. Commun. 111, 518, 1983.

39. Friedman, S. A., Remold-O’Donnel, E., and Piessens, W. F., Cell. Immunol. 42, $213,1979$.

40. Chensue, S. W., Ellul, D., Spengler, M., Higashi, G. I., and Kunkel, S. L., J. Leucocyte Biol. 38, 671, 1985.

41. Kunkel, S. L., Fantone, J. C., Ward, P. A., and Zurier, R. B., In "Progress in Lipid Research" (R. T. Holman, Ed.), pp. 633-640, Pergamon, New York, 1981.

42. Boraschi, D., Censini, S., Bartalini, M., and Tagliabue, A.. J. Immunol. 135, 502, 1985.

43. Hunninghake. G. W. Garrett, K. C., Richerson, H. B., Fantone, J. C., Ward, P. A., Rennard, S. I., Bitterman, P. B., and Crystal, R. G., Amer. Rev. Respir. Dis. 130, 476. 1984.

44. Gordon. D.. Bray. M. A.. and Morley. I., Nature (Iondon) 262, 401, 1976.

45. Demenkoff, J. H., Ansfield, M. J., Kaltreider, H. B., and Adam, E., 124, 1365, 1980.

46. Metzger, A., Hoffeld, J. T., and Oppenheim, J. J., J. Immunol. 127, 1109, 1981

47. Moore, R. N., Urbaschek, R., Wahl, L. M., and Mergenhagen, S. E., Infect. Immunol. $26,408$. 1979.

48. Schnyder, J., Dewald, B., and Baggiolini, M., Prostaglandins 22, 411, 1981.

49. Zurier, R. B., and Quagliata, F., Nature (London) 234, 304, 1971.

50. Kunkel, S. L., Thrall, R. S., Kunkel, R. G., McCormick, J. R., Ward, P. A., and Zurier. R. B., J. Clin. Invest. 64, 1525, 1979.

51. Chensue, S. W., Kunkel, S. L., Ward, P. A., and Higashi, G. I., Amer. J. Pathol. 111, 78.1983.

52. Pinkston, P., Bitterman, P. B., and Crystal, R. G., Nen Engl. J. Med. 308, 793, 1983.

Received March 26, 1986; accepted with revision September 8, 1986 